\title{
Comparative Analysis of Socio-Economics Determinants of Fertility: Malaysia and United Kingdom
}

\author{
Rohana bt Kamaruddin*, Nor Rashidah Zainal \\ Universiti Teknologi MARA, Shah Alam, Malaysia \\ rohana070@salam.uitm.edu.my*, norrashidah@salam.uitm.edu.my
}

\begin{abstract}
The divergence between the literature on fertility decision making and the differences factors on determinants signifies the importance of this study. The study will conduct empirical analysis from the perspective of demographical dimension, socio-economics, intergenerational factors and microeconomics factors that is associated with fertility decision making from the theoretical perspective of quality vs. quantity of children. Order Probit model was employed using the selected sample of female at the age 15 to 49 . The finding revealed educated women in Malaysia and UK decision on the number of children based on their fertility preference and career advancement. The other explanation is based on the relative price change by Becker's demand of children - cost of child-rearing activities, urbanization, opportunity costs of child-bearing.
\end{abstract}

Keywords: Fertility-decision, socio-economics, demographical, intergenerational, microeconomics

\section{Introduction}

Historically, the rapidly increasing population throughout the world has escalated many problems, which include widespread poverty, unemployment, social issues such as inequality, underdevelopment, political unrest, climate change, diseases and other pandemics, reproductive health and many other problems. These have led to many issues that relate to many aspects of life from housing, health, ageing, influx of migrations and clean access of water, and so much more. These also have subsequently contributed to the emergence of doctrine on population by United Nations (UN) and government of the country. However, the fact that the worldwide fertility has declined over the past fifty years was anticipated by demographers and population forecasters, as evidenced by the UN population projections made the 50s and 60 s century. In the early $50 \mathrm{~s}$, there are two distinct demographic groups:

- less developed regions with total fertility rates above 5 children per woman

- less developed regions with average fertility above 3.5 children per woman

Table 1: The World, Development Groups and Major Areas Total Fertility

Total fertility (average number of children per woman)

\begin{tabular}{lrrrr}
$\begin{array}{l}\text { Development group } \\
\text { or major area }\end{array}$ & $1950-55$ & $1970-1975$ & $1990-1995$ & $2005-2010$ \\
\hline World & 4.97 & 4.44 & 3.04 & 2.53 \\
Developed regions & 2.83 & 2.15 & 1.67 & 1.66 \\
Developing regions & 6.08 & 5.36 & 3.38 & 2.69 \\
$\quad$ Least developed countries & 6.55 & 6.75 & 5.77 & 4.53 \\
Other less developed countries & 6.02 & 5.18 & 3.08 & 2.40 \\
Africa & 6.59 & 6.66 & 5.71 & 4.88 \\
Asia & 5.83 & 4.99 & 2.96 & 2.25 \\
Europe & 2.67 & 2.17 & 1.57 & 1.54 \\
Latin America and the Caribbean & 5.86 & 5.02 & 3.02 & 2.30 \\
Northern America & 3.35 & 2.01 & 2.00 & 2.02 \\
Oceania & 3.83 & 3.23 & 2.49 & 2.47 \\
\hline
\end{tabular}

Source: United Nations, Department of Economic and Social Affairs, Population Division (2013). Fertility Levels and Trends as Assessed in the 2012 Revision of World Population Prospects.

The 20 year period (1990-2010) from Table 1 showed that out of the sixth regions, Africa still dominates with more than 5 child per woman. In contrast, in Asia, Latin America and the Caribbean, Northern America and Oceania the number of children ranging from 2 to 3 children per woman; and Europe with lowest fertility below 2 children per woman. The world fertility level are influences by many factors such as demographic, 
socio economics, culture, social and economic conditions. Many reasearch always associated lower fertility wirh industrialized and economically developed country. Table 2 represents a average number of children per woman based on the type of country development.

Table 2: Fertility Rate by World Bank Income Group, 2009

\begin{tabular}{lcc}
\hline Income Group & $\begin{array}{c}\text { Adolescent fertility rate } \\
\text { (per 1000 girls aged 15 -19 years) }\end{array}$ & $\begin{array}{c}\text { Crude death rate (per } \\
\mathbf{1 0 0 0} \text { population) }\end{array}$ \\
\hline Low Income & 110 & 11 \\
Lower -middle income & 223 & 8.5 \\
Upper-middle income & 197 & 7.5 \\
High income & 134 & 8.3 \\
Global & 202 & 8.4 \\
\hline
\end{tabular}

Source: World Health Organization (2013), Global Health Observatory Data Repository

Table 3 provides general characteristics of Malaysia and United Kingdom; indicating some basic informations relating to geographic and socio-economics information. Malaysia and UK represent substantial diversity in many aspects of socio-demographic factors, socio-economics status, cultural and religious factor. Malaysia has a majority of Muslim populations and is a multi-racial country with diversity of culture. Christian is a major religion in the United Kingdom until the 1980s, when Christianity declined and the diversity of the population increased. The two countries also represent substantial diversity in education, income per capita and woman working ratio.

Table 3: Basic characteristics of Malaysia and UK

\begin{tabular}{llc}
\hline Characteristics & United Kingdom & Malaysia \\
\hline Region & Northern Europe & South Eastern Asia \\
$\begin{array}{l}\text { Population (million) } \\
\text { GDP per-capita (US\$) }\end{array}$ & 62,417 & 28,859 \\
$\begin{array}{l}\text { Total fertility rate } \\
\text { (children per women) }\end{array}$ & 18,918 & 9,977 \\
$\begin{array}{l}\text { Female labour-force } \\
\text { participation rate (2009-2013) } \\
\text { Life expectancy at birth (years) }\end{array}$ & $82.4 / 78.3$ & 2.6 \\
$\begin{array}{l}\text { Female/ Male } \\
\text { Gross enrollment rate (\%) }\end{array}$ & $102^{\mathrm{b}}$ & 44 \\
$\begin{array}{l}\text { Secondary } \\
\text { Quality of life index }\end{array}$ & $9.917^{\mathrm{c}}$ & $76.9 / 72.5$ \\
\hline
\end{tabular}

Source: aData from United Nations (2014)

bData are form United Nations Development Programme (2014)

${ }^{c}$ www.economist.com (retrieved 6 March 2014) (Scale 1-10)

The fertility rate in Malaysia is 1 per cent higher than United Kingdom. Such low fertility levels indicate that each country has experienced substantial decline in fertility but the time frame might be different. As for UK total fertility rate is only 1.6, below the replacement level of 2.1 children per woman in every member state of the European Union (EU). According to Grant et al. (2004), there is negative relatioship between fertility and the mean age of women, which cause more older people than the younger youths. This will be serious consequences for policymakers, due to increases in pension and health provisions as people age and therefore fewer tax payers. Another fact is the increasing participation of women in their prime age of 25-54 years in paid work has been driving the employment trends and the gender gaps in labour force participation rate, which linked to the completion of the fertility transition. UK labour force participation rate is 12 percent higher than Malaysia, drove the fertility rate below the replacement rate of 2 children per women. Malaysia 
female labour force participation rate start to increase when women start entering the labour force for family survival. The limitation of this research is the unavailability of secondary data on fertility demographics and socio-economics from Malaysia and UK. This is further analyze on the demographical effect, intergenerational relationship, relative income effect and opportunity cost. The focus will center on female at child bearing age of 15 to 49 years old.

\section{Literature Review}

Rational choice theory is directed on the hypothesis individual/woman react to achieve their individual objective in any situations. Bulatao (2001) stated that to limit fertility is largely seen as a normal process based on individual controls that less fertility make sense for economic and non-economics factors. These theories are interrelated with two major economic approaches associated with fertility change;

- Decreased number of children influenced by income, price and taste (Becker, 1981; Schultz, 1974)

- Supply and demand framework by Easterlin (1978), in which supply are constraint that boundary of usual fertility rate and year of existence (Hirshman, 1994; Kirk, 1996) together with culture and attitudes.

In the field of sociology, the related concept of rational choices is associated with theory of exchange (Wallace and Wolf, 1995). Cain (1983) suggest that family treats highly as having children and as a valuable possession and not replaceable. Indeed, the rational choice theories stress more on the economic justification of rising real wages that will induce the decline in fertility rate in three ways as discussed by Schellekens and Poppel (2012). According to Garlor and Weil (1996), the substitution effect is higher than the family income effect; the increase in a woman salary may increase the price of raising children. The increase in income would influence parents to invest more on quality rather than the quantity of children (Becker et al., 1990). Lastly as real income increases, the demand for children may be less because children are more needed to involve in a labour force.

\section{Methodology}

The ordered probit uses the following form to model the dependent variable using categorical;

$\mathrm{Y}^{*}=\beta^{\prime} \mathrm{X}+\varepsilon$

When $Y_{i}$ takes on multiple qualitative values which can be ranked (ordinal outcomes) such as the number of children coded as from 0 to more than 4 . $\beta^{\prime}$ is the vector of estimated parameters and $X$ is the vector of explanatory variables, $\varepsilon$ is the error term, which is assumed to be normally distributed (zero mean and unit variances) with cumulative distribution denoted by $\theta\left({ }^{*}\right)$ and density function denoted by $\emptyset\left(^{*}\right)$. Given a number of children, household number of children falls in category $n$ if $\mu_{\mathrm{it}-1}<\mathrm{Y}^{*}<\mu_{\mathrm{itt}}$. The fertility data, $\mathrm{Y}^{*}$, are related to the underlying latent variable $Y^{*}$, through thresholds $\mu_{i t}$, where $n=0-4$. The underlying probabilities:

$\operatorname{Prob}(\mathrm{y}=\mathrm{n})=\theta\left(\mu_{\mathrm{it}}-\beta^{\prime} \mathrm{x}\right)-\varnothing\left(\mu_{\mathrm{it}-1}-\beta^{\prime} \mathrm{x}\right), \mathrm{n}=5$

Where $\mu_{0}=0$ and $\mu_{5}=+\infty$ and $\mu_{1}<\mu_{2}<\mu_{3}<\mu_{4}<\mu_{5}$ are defined as five thresholds between which categorical responses are estimated. The threshold $\mu$ show the range of the normal distribution associated with the specific values of the response variable. The remaining parameters, $\beta$, represent the effect of changes in explanatory variables on the underlying scale.

The marginal impacts of factors $\mathrm{x}$ on the underlying injury propensity can be evaluated in the following way:

$\partial \operatorname{Prob}(y=n) / \partial x=-\left[\theta\left(\mu_{i t}-\beta^{\prime} x\right)-\theta\left(\left(\mu_{i t-1}-\beta^{\prime} x\right)\right] \beta, \quad n=5\right.$

Marginal effects computation is meaningful for ordered probit model where the effect of variables $\mathrm{x}$ on the intermediate categories is ambiguous if the parameter estimates are available.

Goodness of fit measure can be obtained by calculating 
$\mathrm{P}^{2}=1-\left[\ln L_{b} / \ln L_{o}\right]$

Where $\ln L_{b}$ is the $\log$ likelihood at convergence and $\ln L_{o}$ is $\log$ likelihood computed at zero. This measure is bounded by zero and one. If all model coefficients are zero, then the measure is zero. Although $\mathrm{P}^{2}$ cannot equal one, a value close to one indicates a very good fit.

Model and Data: Census micro data is from Integrated Public Use Microdata Series (IPUMS) containing information collected on persons and households. The responses of each person and household with the different census questions are recorded in separate variables. However, for this study only female within the household will be analyzed at child-bearing age of 15-49 years. Following the theoretical work of Becker (1960, 1981, 1991) and Becker and Lewis (1973), Sah (1991), Sobel and Arminger (1992), Huan (1997), Cigno (1998), Hondroyiannis (2004), Gyimah et al. (2008), so it is possible for this research to come up with an equation for fertility decision making;

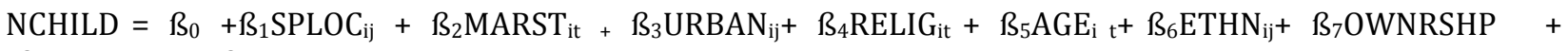
$\beta_{8} \mathrm{OCCISCO}_{i t}+\beta_{9} \mathrm{EDUC}_{\mathrm{it}}+\mu_{\mathrm{t}}$

\section{Variable definitions:}

- $\mathrm{NCHILD}=$ number of children

- SPLOC $=1$ if spouse's location in the household, 0 otherwise

- MARST = marital status

- URBAN = 1 if urban, 0 otherwise

- RELIG = religious belief

- $\mathrm{AGE} \quad=$ childbearing age category (15-49 years old)

- ETHN = ethnicity

- OWRSHP $=1$ if ownership of dwelling, 0 otherwise

- OCCISCO = type of occupation

- EDUC = education attainment

\section{Results and Discussion}

The following is the description of data for the year of 1991. Table 4 present the ordinal scale, the highest categories are women with 3-4 children at 21 percent and only 8 percent have children more than 5 . In Asian countries, the ideal family size tends to band in the range of 3.5 to 4.5 children (ESCAP, 1987). As for UK, the highest categories are women with 1 child and 2 child, 18 percent and 16 percent respectively.

\begin{tabular}{lll}
$\begin{array}{l}\text { Table 4: Descriptive Analysis on Number of Children based on Ordinal Scale - MY and UK } \\
\begin{array}{l}\text { Number of children } \\
\text { in ordinal category }\end{array}\end{array}$ & Percent MY & $\begin{array}{c}\text { Percent } \\
\text { UK }\end{array}$ \\
\hline 0 & 45 & 56 \\
1 & 12 & 18 \\
2 & 14 & 16 \\
$3-4$ & 21 & 7 \\
$>5$ & 8 & 3 \\
\hline Total & 100 & 100
\end{tabular}

Table 5 showed the number of children based on child-bearing age 19 percent are from the age group of 1519 , followed by $20-24$ and $25-29$ at 16 percent and for UK the highest category at the age $30-34$ at $21 \%$. 
Table 5: Descriptive Statistics on Children based on Child-Bearing Age Interval - MY and UK

\begin{tabular}{|c|c|c|}
\hline Age interval & Percent MY & Per cent UK \\
\hline $15-19$ & 19 & 1 \\
\hline $20-24$ & 16 & 8 \\
\hline $25-29$ & 16 & 17 \\
\hline $30-34$ & 15 & 21 \\
\hline $35-39$ & 14 & 17 \\
\hline $40-44$ & 11 & 19 \\
\hline \multirow[t]{2}{*}{$45-49$} & 9 & 17 \\
\hline & 100 & 100 \\
\hline
\end{tabular}

The comparisons were based on proxy of four effects; demographic, intergenerational, relative income and opportunity cost. Ordered probit of ME is used as it provided how change in a response related to change in a covariate (Stata 11 Reference Manual, p.975). For ME for categorical variables show how P (Y=1) is predicted to a change as $X_{k}$ changes from 0 to 1 holding all other $X_{s}$ equal (Cameron \& Trivedi, 2009). The demographic variables of marginal effects between Malaysia and UK presented in Table 6.

Table 6: Comparison of ME Result of Demographic Variables for Malaysia and UK: Ordered Probit for Childless Women

\begin{tabular}{llllll}
\hline \multirow{2}{*}{ Effects } & Variables & Malaysia & & UK & \\
& & ME & $*, * *, * * *$ & ME & $*, * * * * *$ \\
\hline Demographic & Spouse & 0.296 & $* * *$ & $\mathbf{0 . 3 4 0}$ & $* * *$ \\
& Married & $\mathbf{0 . 5 5 7}$ & $* * *$ & -0.391 & $* * *$ \\
& Divourced & $\mathbf{- 0 . 5 2 6}$ & $* * *$ & -0.373 & $* * *$ \\
& Widowed & $\mathbf{- 0 . 5 7 3}$ & $* * *$ & -0.506 & $* * *$ \\
Age 15-19 & $\mathbf{0 . 3 7 5}$ & $* * *$ & -0.012 & $* * *$ \\
Age 20-24 & $\mathbf{0 . 3 3 9}$ & $* * *$ & 0.197 & $* * *$ \\
Age 25-29 & $\mathbf{0 . 2 2 5}$ & $* * *$ & 0.088 & $* * *$ \\
Age 30-34 & 0.032 & $* * *$ & $\mathbf{- 0 . 1 8 0}$ & $* * *$ \\
Age 35-39 & -0.097 & $* * *$ & $\mathbf{- 0 . 3 4 7}$ & $* * *$ \\
Age 40-44 & -0.097 & $* * *$ & $\mathbf{- 0 . 3 8 6}$ & $* * *$ \\
& Malay/White & $\mathbf{- 0 . 1 5 4}$ & $* * *$ & 0.002 & - \\
Chinese/Black & -0.020 & $* * *$ & $\mathbf{- 0 . 1 6 0}$ & $* *$ \\
& Indian/ Asian & -0.089 & $* * *$ & 0.100 & - \\
& Urban/Region & -0.079 & $* * *$ & -0.025 & -
\end{tabular}

Note: ${ }^{* * *}=\mathrm{p}<1 \%,{ }^{* *}=\mathrm{p}<5 \%,{ }^{*}=\mathrm{p}<10 \%, \mathrm{ME}-$ marginal effects, - (not significant)

The proportion of women in Malaysia and UK varied significantly with marital status, age and race in terms of fertility choice. Probability of having a spouse in the household is higher and in UK (34\%) than in Malaysia (30\%), which probably indicates that most spouse in Malaysia is not staying in the household due to work commitment. In terms of marital status, the probability is higher in Malaysia for all categories and more than 50 percent women in Malaysia prefer to have children. In the age category of 15-29 in Malaysia, higher probability of more likely not to have children than in UK. At the age of 30-34, UK with probability of 18 percent prefer not to have children but opposite with Malaysia only 3.2 percent prefer to have children, while at the age of 35-44, both country show the women prefer not to have children but the probability is higher in UK. A woman's fertility decision will depend on the stage of her child-bearing career, influenced number of children and age. In UK, at the age of more than 30 and less than 44 would prefer to have children unlike the women in Malaysia. As in the case of race, only two variables are significant Malay for Malaysia and Black for UK, and quite similar probability of 16 percent prefer not to have children. The last variable on location, only 
significant in Malaysia, which indicate urban prefer not to have more children at probability of 7.9 percent. Study done by Poo \& Nai (1994) on fertility intentions behaviour in Peninsular Malaysia found that significant differences occurred among ethnic group (Malay double than Chinese and Indian in terms of fertility) and rural couples wanted more children than urban. Consequently, these result demostrate that women's preference for children is Malaysia and UK are different in their demographic variables that associated with the age, marital status and race. Table 7 will summarize the result of the marginal effects of the proxy used to the theoretical perpective based on three effects.

Table 7: Comparison of ME Result of Malaysia and UK: Ordered Probit for Childless Women

\begin{tabular}{|c|c|c|c|c|c|}
\hline \multirow[b]{2}{*}{ Effects } & \multirow[b]{2}{*}{ Proxy Variables } & \multicolumn{2}{|c|}{ Malaysia } & \multicolumn{2}{|l|}{ UK } \\
\hline & & ME & $*, * *, * * *$ & ME & $*, * *, * * *$ \\
\hline & Spouse & 0.296 & $* * *$ & 0.34 & $* * *$ \\
\hline \multirow[t]{3}{*}{ Intergenerational } & Married & -0.557 & $* * *$ & -0.391 & $* * *$ \\
\hline & Divourced & -0.526 & $* * *$ & -0.373 & $* * *$ \\
\hline & Widowed & -0.573 & $* * *$ & -0.506 & $* * *$ \\
\hline \multirow[t]{4}{*}{ Relative Income } & Ownership & 0.066 & $* * *$ & -0.043 & $* * *$ \\
\hline & Education & & & & \\
\hline & Secondary & 0.070 & $* * *$ & 0.098 & $* * *$ \\
\hline & University & 0.085 & $* * *$ & 0.052 & $* * *$ \\
\hline \multirow[t]{5}{*}{ Opportunity Cost } & Education & & & & \\
\hline & Secondary & 0.070 & $* * *$ & 0.098 & $* * *$ \\
\hline & University & 0.085 & $* * *$ & 0.052 & $* * *$ \\
\hline & Legislator & -0.047 & - & 0.196 & $* * *$ \\
\hline & Operators & 0.033 & - & 0.211 & $* * *$ \\
\hline
\end{tabular}

Note: ${ }^{* * *}=\mathrm{p}<1 \%,{ }^{* *}=\mathrm{p}<5 \%,{ }^{*}=\mathrm{p}<10 \%, \mathrm{ME}-$ marginal effects, - (not significant)

Intergenerational effects: In both estimation models, spouse living in the same household in both countries with the probability is about 30-35 percent preferred not to have children. This finding indicates that existence of spouse in the family surrounding is not important with the assumptions as long the spouse provided a source of income to the family. As for marital status (married, divorced and widowed) suggests that chains of relationship are important in deciding the number of children, however the probability is higher in Malaysia than in UK.

Relative income effect and opportunity cost: Table 7 shows that the relative income effects reveal higher probability of ownership for women in Malaysia with 6.6 percent more likely not to have children if they do not own a house. To own a house is a proxy of women asset, relative cost of having children to a family is not surely affecting the source of income which adds to family endowments. In this study, the finding of owning a house is expected to associate with increase number of children, other things being equal (Shultz, 1981; 1994).

As for education show that women in both country prefer not to have children, with the probability of less than 10 percent. However, the effects are higher in Malaysia for women with university qualification (8.5\%) than in UK (5.2\%), but the opposite result for secondary level. In terms of employment level, the MEs are significant for UK, higher probability for lower level occupation. There are negative associations between the high level of wage returns of employment and the level of fertility (Becker and Lewis, 1974). They suggest further that the income elasticity of demand for child quantity exceeded positive income elasticity for child quantity which means more income and less fertility. In this case one should not assume that children (quantity) are an inferior good for which income effects are negative, or to show increases in women's value of their time in the modern economy caused the decline in fertility. 
The ME for education which is proxy for opportunity cost for a woman are higher as the education level increase in Malaysia but lower in UK. This result indicates that as the opportunity cost of raising children increases, household prefer fewer children. The negative association measure of relative income effect supports the quality-quantity theory and indicates women prefer less but higher quality children. Willis (1973) found that women's education was assumed to enhance women's productivity only in the market, and thereby increase the relative price of home production and decrease their demand for fertility. The wage return from higher education would increase demand for schooling and indirectly would decrease the demand for fertility. After analyzing the effect of relative income and opportunity cost of women in both countries, this study can conclude that the result follow the neoclassical theory of demand for children (Becker, 1981; Becker \& Lewis, 1973).

\section{Conclusion}

The finding revealed women in Malaysia and UK with higher level of education is strongly associated number of children based on their choice and career advancement rather that thinking on number of children. The other explanation is based on the relative price change by Becker's demand of children - cost of child-rearing activities, urbanization, opportunity costs of child-bearing. Consequently, this research indicates a positive scenario in the overall fertility decision making, although it is at the declining trend, but women today are concern more on the quality of children they produced for the nation.

Acknowledgement: Author wish to thank Professor Richard Harris, Head of Department of Economics and Finance, Durham University Business School, United Kingdom for his constructive review of this study during author sabbatical period QA

\section{References}

Becker, G. S. (1960). An Economic Analysis of Fertility. In G. Becker, J. S. Duesenberry \& B. Okun (Eds.), Demographic and Economic Change in Developed Countries, Princeton, pp. 209-231

Becker, G. S., Murphy, K. M. \& Tamura, R. (1990). Human Capital, Fertility, and Economic Growth. Journal of Political Economy, 98, S12-S37.

Becker, G. S. (1981). Altruism in the Family and Selfishness in the Market Place. Economica, 48, 1-15.

Becker, G. S. (1991). A Treatise of the Family. London: Harvard University Press

Becker, G. S. \& Lewis, H. G. (1973). On the Interaction between the Ouantity and Quality of Children. Journal of Political Economy, 81, 279-299

Becker, G. S. \& Lewis, G. H. (1974). Interrelation Between Quantity and Quality of Children, in T.W, Schultz (eds), Economics of the Family: Marriage, Children and Human Capital, PP. 81-90, Chicago, University of Chicago Press.

Bulatao, R. (2001). Introduction. Population and Development Review, 9, 688-702.

Cain, M. (1983). Fertility as Adjustment to Risk. Population and Development Review, 9, 688-702

Cigno, A. (1998). Fertility Decisions When Infant Survival is Endogenous. Journal of Population Economics, 11, 21-28.

Cameron, A. C. \& Trivedi, P. (2009). Microeconometrics Using Stata, Stata Press, College Station, TX, 2009

ESCAP, (1987). Population Research Leads 26:8

Easterlin, R. A. (1978). The Economic and Sociology of Fertility: A Synthesis, 57-113 in C. Tilly, ed., Historical Studies of Changing Fertility. Princeton University Press

Grant, J., Hoorens, S., Sivadasan, S., Loo, M., DaVanzo, J., Hale, L., Gibson S. \& Butz W. (2004). Low fertility and population ageing: Causes, consequences, and policy options. UK: European Commission. RAND Corporation

Garlor, O. \& Weil, D. N. (1996). The Gender Gap, Fertility, and Growth. American Economic Review, 86(3), 374387.

Gyimah, S. O., Takyi, B. \& Tenkorang, E. Y. (2008). Denominational Affiliation and Fertility Behaviour in an African Context: An Examination of Couple Data from Ghana. Journal of Biosocial Science, 40, 445458.

Hirshman, C. (1994). Why Fertility Changes? Annual Review Sociology, 20, 203-33. 
Huan, N. D. (1997). A Socioeconomic Analysis of the Determinants of Fertility: The Case of Vietnam. Population Economics, 10, 251-271.

Hondroyiannis, G. (2004). Modeling household fertility decision in Greece. The Social Science Journal, 41, 477 483

Kirk, D. (1996). Demographic Transition Theory. Population Studies, 50, 361-387

Minnesota Population Center, Integrated Public Use Microdata Series, International: Version 6.2 [Machinereadable database]. Minneapolis: University of Minnesota, 201

Sah, R. K. (1991). The Effect of Child Mortality Changes on Fertility Choice and Parental Welfare. Journal of Political Economy, 99(3), 582-606.

Sobel, M. E. \& Arminger, G. (1992). Modelling Household Fertility Decision: A Nonlinear Simultaneous Probit Model. Journal of the American Statistical Association, 87, 38-47

Schellekens, J. \& van Poppel, F. (2012). Marital Fertility Decline in the Netherlands: Child Mortality, Real Wages, and Unemployment, 1860-1939. Demography, 49(3), 965-88.

Schultz, T. P. (1974). Birth rate changes over space and time: a study of Taiwan, in: T.W. Schultz, ed., Economics of the family (University of Chicago Press, Chicago, IL)

Schultz, T. P. (1994). Mortality decline in the low-income world: causes and consequences. AEA Papers and Proceedings, 83, 337-342.

Schultz, P. (1981). Economics of Population. Reading, MA: Addison Wesley.

Stata Press. (2012). Stata Base Reference Manual, Release 11. College Station, TX: Stata Press Quality of Life Index retrieved at www. economist.com

United Nations. $(2013,2014)$. Department of Economic and Social Affairs, Population Division.

United Nations, Department of Economic and Social Affairs, Population Division. (2013). Fertility Levels and Trends as Assessed in the 2012 Revision of World Population Prospects.

Wallace, R. A. \& Wolf, A. (1995). Contemporary Sociology Theory: Continuing the Classical Tradition. Englewood Cliffs, NJ. Prentice Hall.

Willis, R. J. (1973). A new approach to the economic theory of fertility behaviour. Journal of Political Economy, 81(S2), S14-S64.

World Health Organizations, Global Health Observatory Data Repository Assessed at pps.who.int/gho/data/view.main.2060. 